\title{
Influence of Die Threading and Finishing Length in the Thread- Rolling Process Using Flat Dies: A Numerical Analysis
}

\author{
L. Giorleo ${ }^{1}$ (I) $\cdot$ M. Cartapani ${ }^{1}$
}

Received: 18 June 2021 / Accepted: 26 September 2021 / Published online: 29 October 2021

(C) The Author(s) 2021

\begin{abstract}
In this paper, a numerical analysis of the cold thread-rolling process using flat dies is presented as a function of the die geometry design. Five die geometries with different threading and finishing ratios were modelled to induce different screw deformation rates. An analytical method was proposed by the authors to design die geometries as a function of screw roll rotation. Screw geometry accuracy, induced stress, and die wear were selected to compare the tested geometries. The results showed that three screw rotations in the threading step were sufficient to guarantee good geometry accuracy. Moreover, the results highlighted that die wear is the most affected parameter among all the tested geometries. Finally, a new solution was proposed by the authors to obtain uniform wear and reduce the die length.
\end{abstract}

Keywords Bulk metal forming - Die wear .

Thread-rolling · FEA

\section{Introduction}

Thread-rolling in a flat die process is a cold-forming process characterised by the use of two dies: one is kept fixed while the other is operated with an alternative work feed. The process is performed in one pass, starting from one end of the fixed die, the work-piece is rolled and deformed as it moves towards the opposite end and ejected. The dies are grooved with a geometry corresponding to the

\section{Giorleo}

luca.giorleo@unibs.it

1 Department of Mechanical and Industrial Engineering, University of Brescia, Brescia, Italy development of the desired thread and inclined by an angle characterising the thread helix. Thus, the tools represent the mirrored geometries of the pieces that will be obtained. The two dies are arranged such that the crests of one are aligned with the grooves of the other. Figure 1 illustrates the process scheme.

The thread-rolling process has many advantages over machining processes, such as low manufacturing cost, high material utilisation without chipping, superior mechanical properties due to plastic forming, low forming load owing to the incremental process, and high production speed [1]. Hence, the thread-rolling process using flat dies is widely used by the automotive industry.

Various authors have focused their research on threadrolling topic to improve process simulation accuracy. The three-dimensional numerical modelling of thread-rolling was developed by [2,3] to analyse the effect of mesh density and states of stress during the process. [4] developed a three-dimensional model of a flat die rolling process incorporating blank rotation, die movement, and pitch angle on die faces. The results showed that deformation was concentrated on the surface and subsurface layers. Moreover, the core was deformed slightly. Based on [4] results, [5] analysed the effect of varying thread form, friction factor, flow stress, and blank diameter on the effective strain and thread height. The research suggested that thread form affects the effective strain generated at the root and crest during rolling. Moreover, the friction factor has little impact on thread form or height at low values, which is typical in cold forming. As the work hardening rate increases, the crest profile tends to change from a concave to a convex shape. [6] focused the research activity the friction coefficient evaluation. They found an experimental friction coefficient $(\mu=0.15)$ using a tribological test. However, assuming higher friction coefficients 


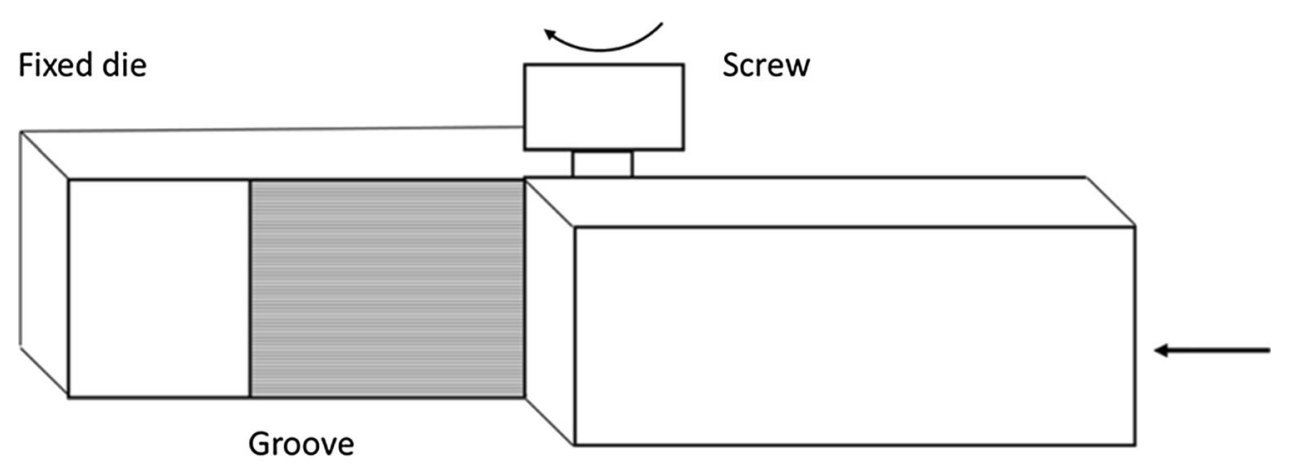

Moving die

Fig. 1 Thread-rolling process using flat dies

( $\mu=0.30$ ) leads to a better accuracy between the numerical model and experimental measurements. The conflict between the experimentally measured friction coefficients and numerical results was due to the finding that the relative sliding velocity within the contact zone was very low. Hence, the static friction was dominant. Other authors used numerical analysis to improve the process performance [7] that determines the optimal modes for rolling thread on a titanium alloy work-piece. The authors stated that imposing a rolling speed equal to $5.7 \mathrm{~m} / \mathrm{min}$ increased the product strength up to $30 \%$ [8] provided detailed engineering information for the thread-rolling of micro-sized screws. Moreover, they investigated the effect of friction coefficient and relative vertical position between the stationary die and moving die using finite element simulation finding that a shear friction factor of 0.9 is appropriate for preventing slip between dies and raw material. The research also demonstrated that the relative position of the two dies has to be set to the half-length of the pitch to maintain the continuous thread profiles. Evaluation and optimisation of thread forces is another important topic investigated by [9], which presents a novel setup for the direct measurement of forces in thread-rolling operations. This setup allows the measurement of force signals for the feed $(z)$ and radial work-piece $(y)$ directions. [10,11] proposed an analytical model to predict the maximum load and mode of failure of threaded steel fasteners at high strain rates. The authors demonstrated that several parameters have an influence on the failure mode, such as length of thread engagement, grip length, and strain rate. The threaded assembly tests showed that the number of threads in the grip length changed the failure mode. Moreover, new solutions are available, as studied by [12]. They described a thread-rolling method that consists of thread forming using two flat wedges provided with special grooves designed for thread forming. The shapes of grooves in the cross section correspond to the thread cross-section contour. The advantage of the proposed solution is the possibility of thread forming in any part of shaft.

\section{Motivation}

As described in the introduction, a main challenge in the thread-rolling process was to set the numerical software to simulate the process correctly. Particularly, the friction coefficient. Former studies increased the software accuracy, which provided the possibility of using a numerical approach to optimise this process. To increase the knowledge about thread-rolling using flat dies, the authors used a numerical approach to investigate how the die geometry design affects the process. Figure 2 shows a side view of a typical die geometry. As illustrated in the three different zones, the threading step is characterised by the screw being deformed, the finishing step adjusts the desired geometry, and the exit zone allows the screw to be pushed out from the die.

Generally, the main phenomena that affects the tool life in thread-rolling process is die wear. Particularly, the first millimetre is critical because of the amount of deformation induced and the wear experienced. By keeping the die length $\left(L_{D i e}\right)$ constant, it is possible to increase the threading step to decrease the induced deformation rate. However, this results in the reduction of the finishing step

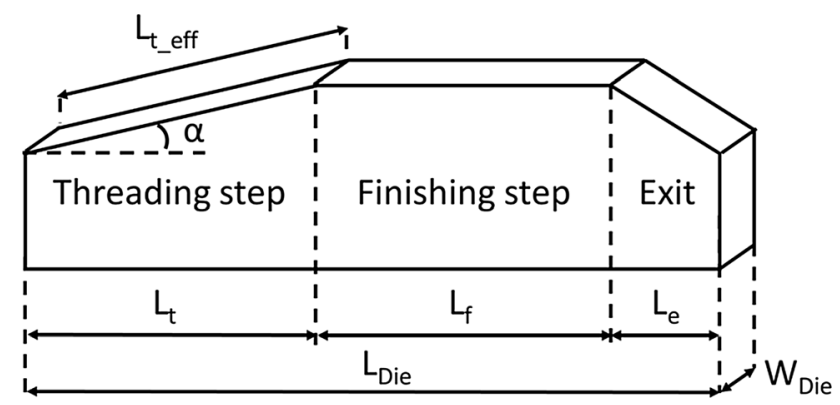

Fig. 2 Die design 
and decreased geometrical accuracy. A trade-off must be identified to achieve good quality parts with less die wear. Starting from an industrial case study, the authors analysed the effect of different sets of threading and finishing cycles in terms of geometrical accuracy, die stress, and wear. The results emphasised the possibility of realising new tool geometry saving cost and achieving good performance in terms of wear and accuracy.

\section{Materials and Methods}

In this study, the thread-rolling process of the M9 $\times 1$ screw was selected as a case study because it is used extensively for various applications in the automotive industry. Table 1 lists the geometry and material data of M9 $\times 1$ screws.

Five different die geometries were designed as a function of threading $\left(L_{t_{-} e f f}\right)$ and finishing $\left(L_{f}\right)$ die length. For this research, the authors imposed a constant die length $\left(L_{D i e}\right)$ and exit zone length $\left(L_{e}\right)$ and selected five different $L_{t \_e f f}$ and $L_{f}$ lengths as a function of the number of screw rotations. Coherent with the industrial environment, a total number of 7 screw roll rotations $\left(n_{T O T}\right)$ were considered. The steps followed for evaluating the tool die parameters

Table 1 Thread geometry and material

\begin{tabular}{lll}
\hline & Initial & Final \\
\hline Screw diameter $\left(\varphi_{t}\right)[\mathrm{mm}]$ & 8.3 & 8.7 \\
Pitch $[\mathrm{mm}]$ & 0 & 1 \\
Material & $34 \mathrm{CrMo} 4$ & \\
\hline
\end{tabular}

$L_{t}, L_{f}$, and $\alpha$ as functions of screw rotation in the treading $\left(n_{t}\right)$ and finish $\left(n_{f}\right)$ steps are summarised in Fig. 3.

Based on the methods shown in Fig. 3, five different values of $n_{t}$ were tested, varying from a minimum of two to a maximum of six screw rotations. Thus, the screw finishing rotation was consequently imposed in the range between five and one rotation. Table 2 shows all the modelled die geometries.

To simulate the thread-rolling process, the software COLDFORM by Transvalor was selected. Several preliminary tests were simulated to obtain a good balance between the screw geometry, mesh size, die material, and thread inclination to reduce the simulation time. Additionally, to reduce the computational time, the following constraints were set:

- The screw height was reduced to $7 \mathrm{~mm}$;

- The die width $\left(W_{D i e}\right)$ was set to be $15 \mathrm{~mm}$;

- An adaptive mesh was adopted, whose element size varied from $2 \mathrm{~mm}$ at the boundary to $0.125 \mathrm{~mm}$ at the centre;

- The moving and fixed dies were simulated as rigid;

- A linear straight thread profile was simulated;

Owing to these assumptions, the simulation time was reduced by $90 \%$ (from 522 to $36 \mathrm{~h}$ ). The final setup based on the preliminary test results is reported in Fig. 4, while Table 3 lists all the other parameters needed to simulate the process. The friction coefficient was set coherently with the data found in the literature $[6,13]$.

The thread-rolling simulation results were compared by considering the part geometry, screw stress, and die wear. The geometrical analysis was set by comparing the part mesh with the final geometry after each screw rotation. The

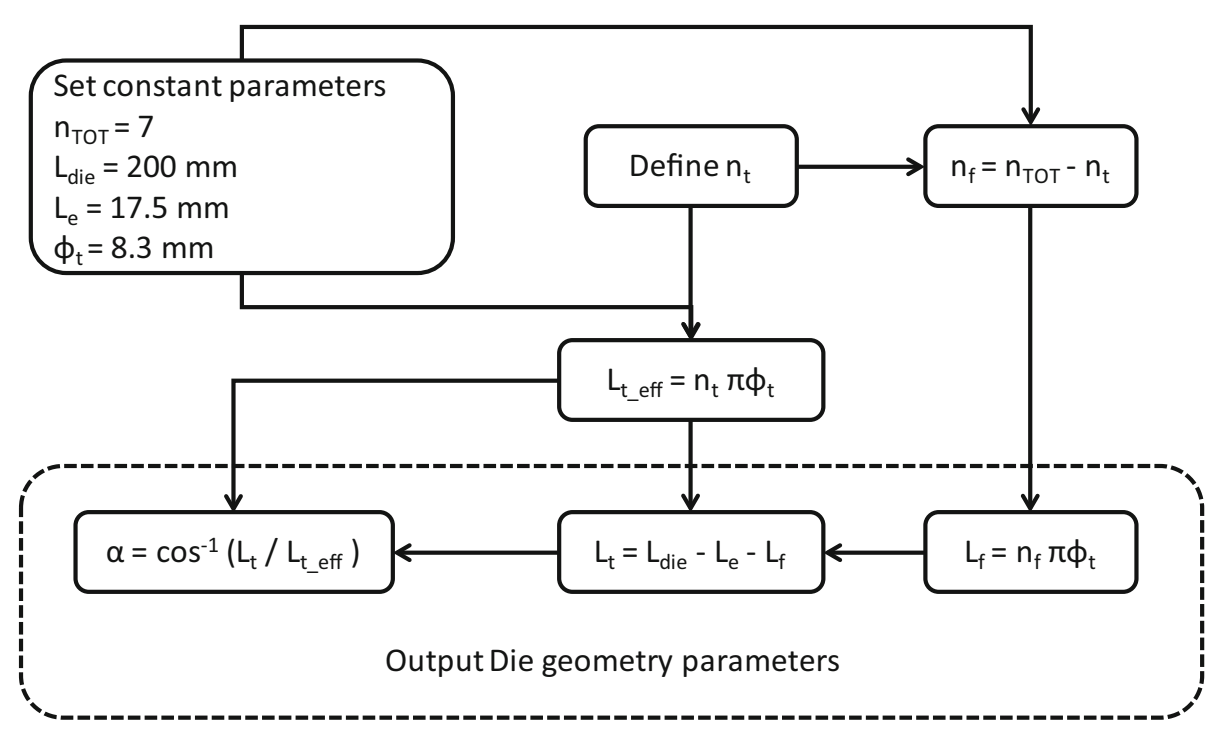

Fig. 3 Scheme of geometry parameter selection 
Table 2 Designed tool die geometries

\begin{tabular}{lllllrrrrr}
\hline Test \# & $n_{t}$ & $n_{f}$ & $\varphi_{t}(\mathrm{~mm})$ & \multicolumn{1}{l}{$\begin{array}{l}L_{t \_e f f} \\
(\mathrm{~mm})\end{array}$} & $L_{f}(\mathrm{~mm})$ & $L_{\text {Die }}(\mathrm{mm})$ & $L_{e}(\mathrm{~mm})$ & $L_{t}(\mathrm{~mm})$ \\
\hline t2_f5 & 2 & 5 & 8.3 & 52.1504 & 130.38 & 200.00 & 17.5 & 52.1499 \\
t3_f4 & 3 & 4 & 8.3 & 78.2257 & 104.30 & 200.00 & 17.5 & 78.2251 & 0.0045 \\
t4_f3 & 4 & 3 & 8.3 & 104.3009 & 78.23 & 200.00 & 17.5 & 104.3003 & 0.0032 \\
t5_f2 & 5 & 2 & 8.3 & 130.3761 & 52.15 & 200.00 & 17.5 & 130.3756 \\
t6_f1 & 6 & 1 & 8.3 & 156.4513 & 26.08 & 200.00 & 17.5 & 156.4508 & 0.0029 \\
\hline
\end{tabular}

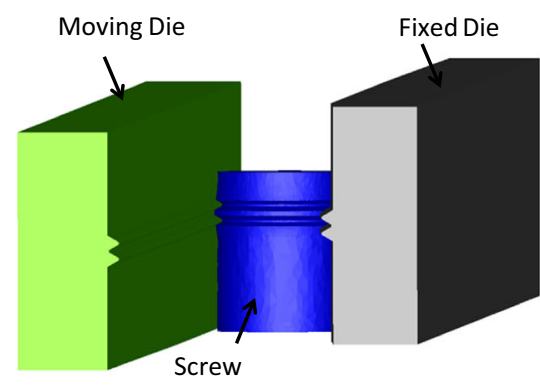

(a) Thread-rolling process scheme

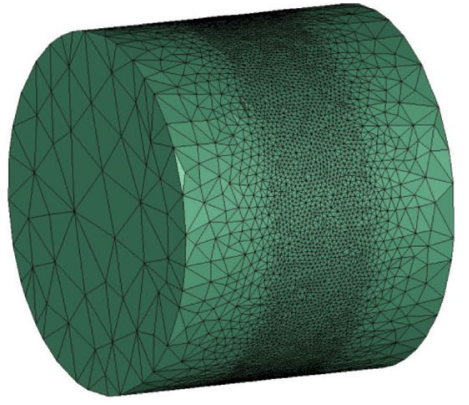

(b) Adaptive mesh

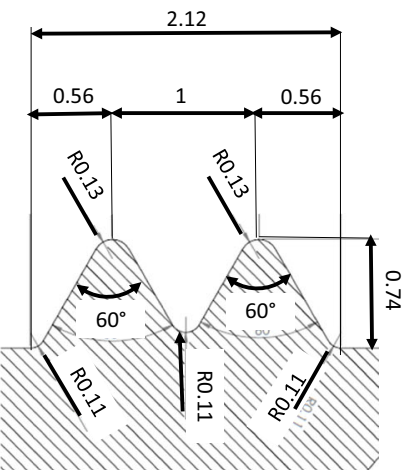

(c) Thread profile

Fig. 4 FEM process simulation

Table 3 Thread-rolling modelling input parameters

\begin{tabular}{ll}
\hline \# screw nodes & 14,000 \\
\# moving/fixed die nodes & 130,000 \\
Moving die feed rate $(\mathrm{mm} / \mathrm{s})$ & 1500 \\
Production time $(\mathrm{s})$ & 0.08 \\
Die/thread starting interference $(\mathrm{mm})$ & 0.15 \\
Die material & High Speed Steel AISI M2 \\
Friction coefficient $(\mu)$ & 0.3 \\
Working temperature $\left({ }^{\circ} \mathrm{C}\right)$ & 20 \\
\hline
\end{tabular}

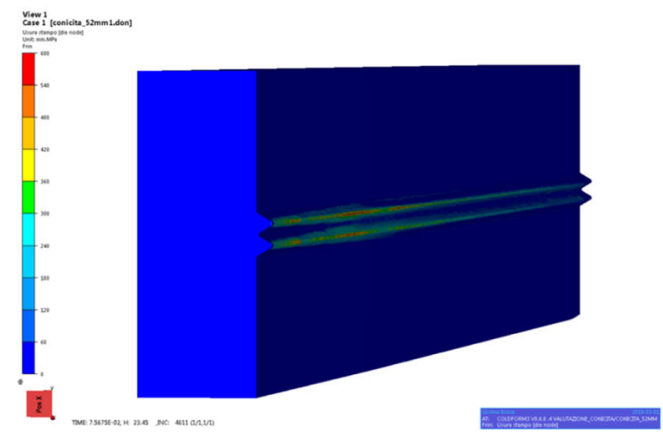

(a) Example of die damage trend for Test t2_f5 comparison was executed using the commercial software GOM. For stress analysis, the effective stress evaluated according to the von Mises criteria was extracted from the COLDFORM software. The stress experienced on the screw cross section was measured and compared as a function of screw rotation. For die wear evaluation, the software allows an indirect method that is the evaluation of a die damage, a parameter that is function of the stress and the screw/die speed. Die damage is direct proportional to the die wear. Die damage formula is shown in Eq. 1.

Fig. 5 Die damage sampling methods 


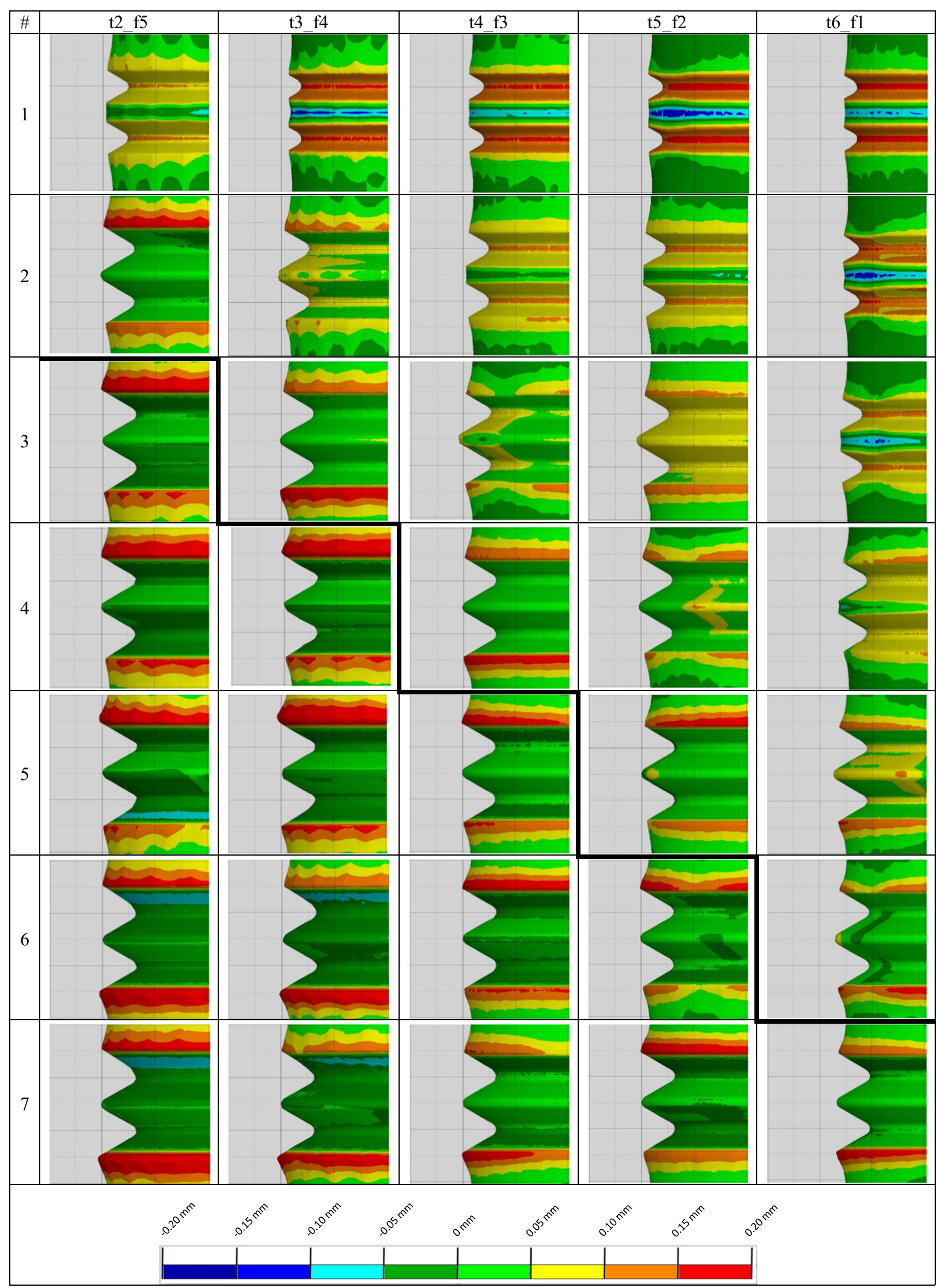

Fig. 6 Thread cross-section inspection analysis as a function of number of roll (column) and die geometry (raw), grid spacing (0.5 mm) 
Die damage $=\int \sigma_{n}\left|v_{\text {screw }}-v_{\text {Die }}\right| d t$

where:

$\sigma_{n}=$ shear stress $[\mathrm{MPa}]$.

$v_{\text {screw }}=$ screw peripheral speed $[\mathrm{mm} / \mathrm{s}]$.

$v_{\text {die }}=$ Die speed $[\mathrm{mm} / \mathrm{s}]$.

To evaluate the die damage trend, the thread peak data where higher wear was registered were acquired (Fig. 5a). Three sampling lines were introduced parallel to the thread profile: one located on the peak (line 2) and the other two at a distance of $0.15 \mathrm{~mm}$ (line 1) and $-0.15 \mathrm{~mm}$ (line 3 ) from the thread peak. Figure $5 \mathrm{~b}$ shows the proposed scheme. For each line, a sampling frequency of $0.9 \mathrm{~mm}$ was adopted to obtain two hundred samplings per line.

\section{Results}

In this section, the main results of the simulated test are reported. Figure 6 shows the evolution of the tread profile on the screw. In Fig. 6, a step dark line was added to highlight the separation between the threading and finishing steps. In particular, in each raw the dark line defines the end of threading and the beginning of finishing. As observed in all tests, the tread profile was obtained after the treading step was in the range of $\pm 0.05 \mathrm{~mm}$. However, the finishing step does not improve the obtained geometry. Moreover, in all tests, a material increment was recorded on the boundary deformation zone (red zone on the tread side). This phenomenon is a consequence of the constraint imposed for simulation. Furthermore, the single linear tread profile allows the material to flow in that region.

The effective stress (von Mises) on the screw cross section was analysed after each screw rotation. Figure 7 shows the FEM analysis of all geometries. The maximum value of stress, which changes in the range of 1200-900 MPa was achieved in the last threading step, was located in the screw zone that was in contact with the thread. The main difference observed between the tested geometries is the stress distribution in the screw core: the higher the number of revolution rolls in the treading step, lower the stress registered inside the screw. In the finishing step, a decrease in effective stress, which affected a maximum of $40 \%$ of the screw cross section, was observed with the exception of Tests $\mathrm{t} 2$ f 5 and $\mathrm{t} 3$ _f 4 , where high stresses were measured in the first finishing step.

For die wear analysis, the die damage trend evaluated at the thread peak (line 2) at a distance of $\pm 0.15 \mathrm{~mm}$ from the peak (line 1,3) is shown in Fig. 8 as a function of $L_{t-e f f}$ and $L_{f}$. To analyse the results properly, vertical lines were plotted on each graph with the starting/finishing duration of each screw round.
Figure 8 shows the different die damage trend for the tested geometry. In this figure, increasing and decreasing trends can be observed for the finishing step for Tests t2_f5 and t3_f4 (Fig. 8a and b). Apart from the similar trend, Test t2_f5 achieved the highest peak of $600 \mathrm{MPa} \mathrm{mm}$. Test t4_f3 and t5_f2 showed a similar trend characterised by increasing die wear until a value of approximately $300 \mathrm{MPa}$ mm was achieved in the first half screw rotation. Thereafter, the die wear reached a constant trend of $100 \mathrm{MPa}$ mm (Fig. 8c and d). The initial die wear trend of Test t6_f1 is coherent with Tests t4_f3 and t5_f2 with an average peak of $250 \mathrm{MPa} \mathrm{mm}$ in the first half round. Thereafter, the average peak decreases to $100 \mathrm{MPa} \mathrm{mm}$. After the first round, die wear has an increasing trend and reaches a peak of $350 \mathrm{MPa} \mathrm{mm}$ in the last threading step. Thereafter, a decreasing trend was recorded due to the finishing step.

\section{Discussion}

The results of this study regarding the effect of threading and finishing step length in screw production are summarised below:

- The geometrical analysis after the threading step suggests that each screw was produced correctly. Therefore, the increase in $L_{t \_e f f}$ length to obtain a soft deformation does not affect the screw accuracy. Moreover, the geometrical results suggest that it is possible to reduce the finishing step length because only one revolution is sufficient to obtain a screw with a thread in the range of $\pm 0.05 \mathrm{~mm}$.

- The stress analysis highlights that the main effect of the different geometries tested is achieved to the screw cross section. Particularly, imposing a gradual deformation (Test t6_f1) resulted in lower stress distribution in the screw core. However, the maximum stress achieved was similar in all tests. This behaviour is coherent with the characteristics of the cold forming process. In thread-rolling, forming forces are generated by the constricting the material to pass through the die gap. Thus, material deformation resistance and rigidity of the machine generates the stress on the dies and work-piece. Since the quantity of material to be deformed is same and the yield value of the processed material is unique for the different configurations, the required strain energies are equivalent and so the maximum stress achieved. Compared to other parameters, die wear was primarily affected by different geometries. From Fig. 8, it can be observed that the deformation induced by the first half round of the threading step on the screw, after which the wear 


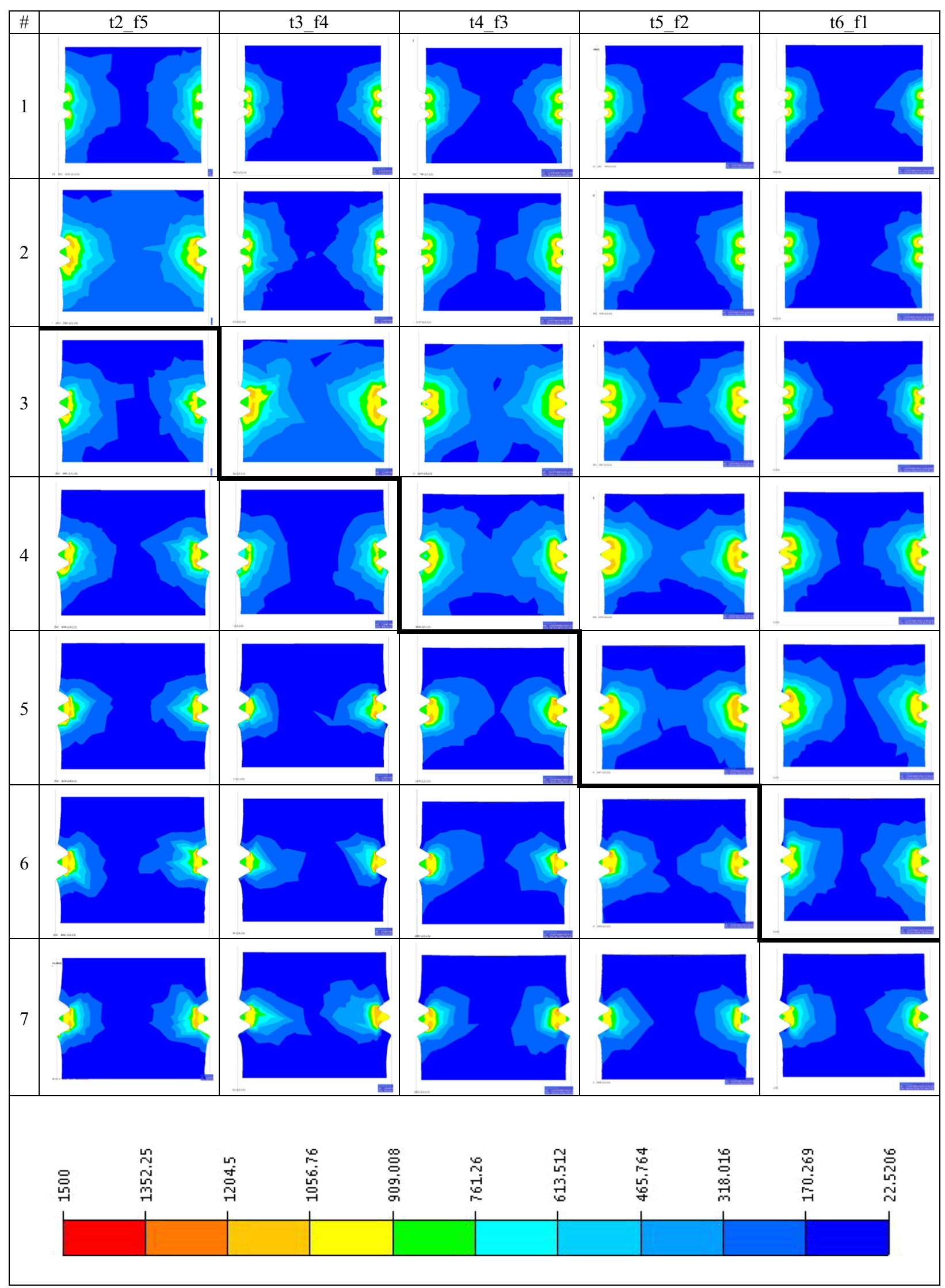

Fig. 7 Von Mises stress (MPa) as a function of number of rolls (column) and die geometry (raw) 
decreases rapidly, is critical for die wear. Additionally, a linearly increasing trend was observed with the slope angle inversely proportional to the $L_{t}$ eff length starting from the second threading round.

- The peak damage registered in the initial round is attributable to the kinematics of the process along that portion of the tool. Furthermore, the screw changes its state from stationary to roto-translatory. Additionally, it can be considered that sliding friction, which is characterised by a static friction coefficient, is present between the part and tool. This phenomenon is coherent with results reported in [6]. However, in the following

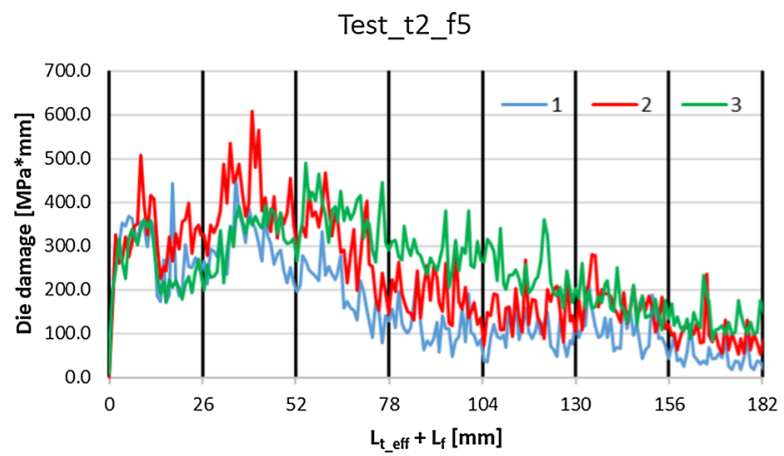

(a)

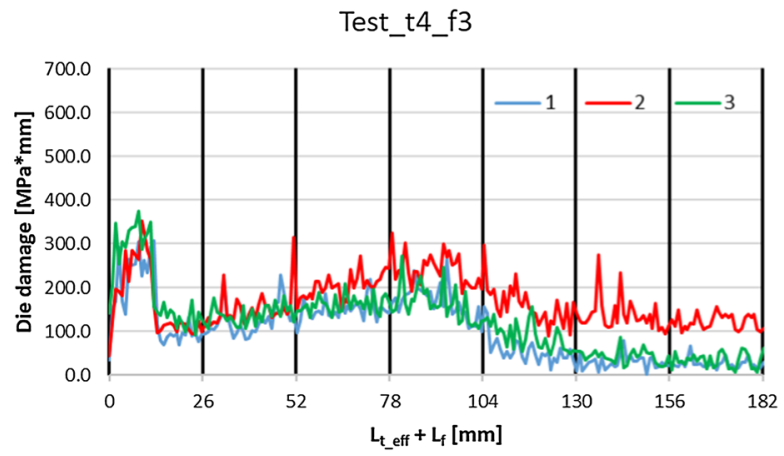

(c) millimetres, when the screw is in roto-translatory motion and completed the first half revolution, the friction change from static to sliding characterised by a lower coefficient.

To summarise, the main effect due to an increase in the threading step is primarily the reduction of die wear, which is a constant trend except for the first half round. This phenomenon is interesting because reducing the die damage peaks is correlated to die working life. Another important finding is that the die damage reduction is higher between Test $\mathrm{t} 3$ _f 4 and $\mathrm{t} 4 \mathrm{f} 3$, where the acquired peaks change from 500 to $300 \mathrm{MPa} \mathrm{mm}$ (40\% reduction). This

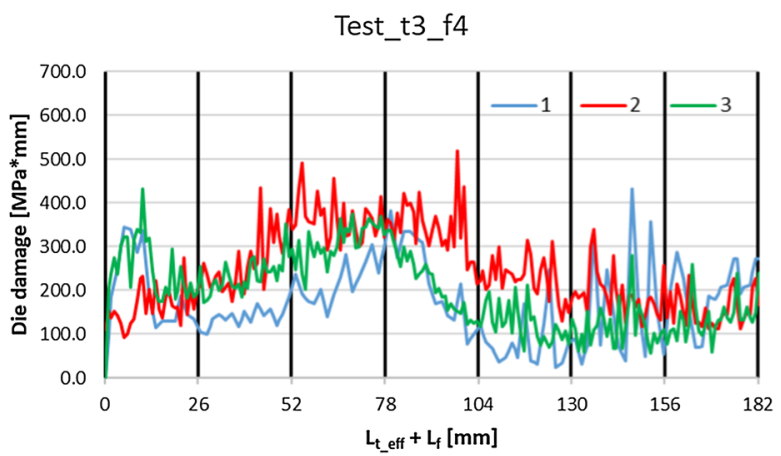

(b)

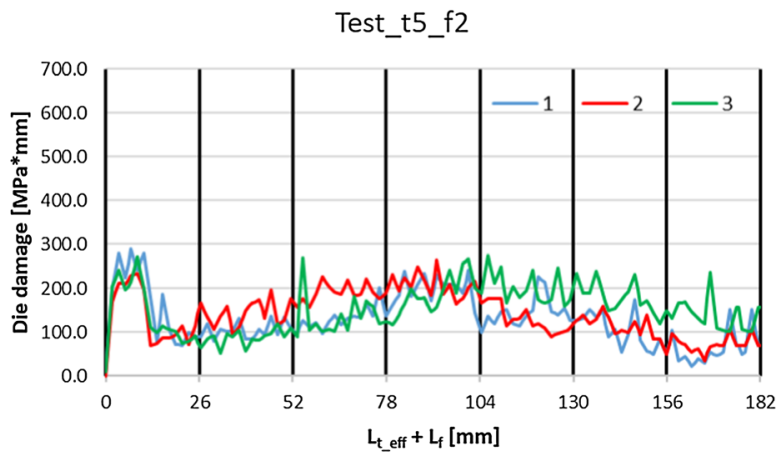

(d)

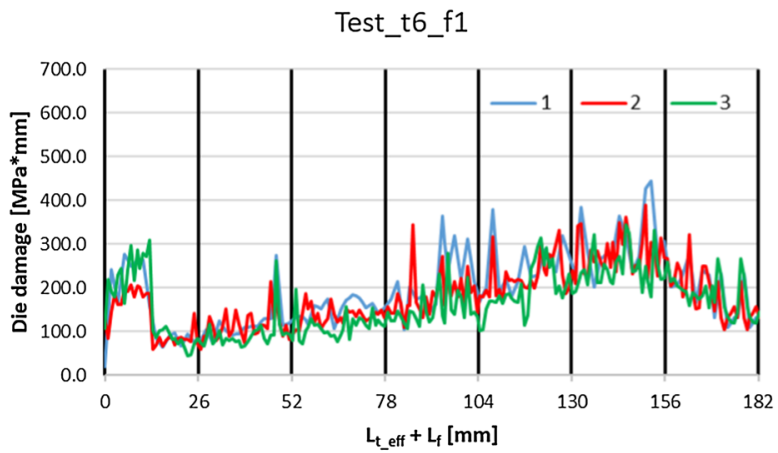

(e)

Fig. 8 Die damage trend 
comparison, coupled with the results of geometrical and physical analysis, opens the possibility of eliminating one finishing step to generate a new die design ( $t 4$ _f 2 ), which decreases material cost by reducing the dimension of the die length.

\section{Conclusion}

In this study, the threading and finishing steps of M9 screw production were investigated. The numerical results highlight the deformation-induced impact of die wear. Additionally, the wear trend achieved the peak value in the first screw-half round. Another important result was achieved with respect to the finishing step length. More than two screw rotations could not improve the benefits of the finishing production process. This preliminary study opens the way to redesign the die length by considering a customised die with a specific ratio between the threading and finishing steps.

Funding Open access funding provided by Università degli Studi di Brescia within the CRUI-CARE Agreement.

\section{Declarations}

Conflict of interest The authors declare that they have no conflict of interest.

Open Access This article is licensed under a Creative Commons Attribution 4.0 International License, which permits use, sharing, adaptation, distribution and reproduction in any medium or format, as long as you give appropriate credit to the original author(s) and the source, provide a link to the Creative Commons licence, and indicate if changes were made. The images or other third party material in this article are included in the article's Creative Commons licence, unless indicated otherwise in a credit line to the material. If material is not included in the article's Creative Commons licence and your intended use is not permitted by statutory regulation or exceeds the permitted use, you will need to obtain permission directly from the copyright holder. To view a copy of this licence, visit http://creativecommons. org/licenses/by/4.0/.

\section{References}

1. H. Tschaetsch, Metal Forming Practise (Springer, Berlin, 2006)
2. J.A. Martin, Fundamental finite element evaluation of a three dimensional rolled thread form: Modelling and experimental results, American Society of Mechanical Engineers, Pressure Vessels and Piping Division (Publication) PVP, 373, pp. 457-461 (1998)

3. J.A. Martin, A mesh density study for application to large deformation rolling process evaluations, American Society of Mechanical Engineers, Pressure Vessels and Piping Division (Publication) PVP, 373, pp. 177-181 (1998).

4. J.P. Domblesky, F. Feng, Two-dimensional and three-dimensional finite element models of external thread rolling. Proc. Inst. Mech. Eng. Part B J. Eng. Manuf. 216(4), 507-517 (2002). https://doi.org/10.1243/0954405021520201

5. J.P. Domblesky, F. Feng, A parametric study of process parameters in external thread rolling. J. Mater. Process. Technol. 121(2-3), 341-349 (2002). https://doi.org/10.1016/S09240136(01)01223-7

6. P. Groche, P. Kramer, Numerical investigation of the influence of frictional conditions in thread rolling operations with flat dies. Int. J. Mater. Form. 11(5), 687-703 (2018). https://doi.org/10. 1007/s12289-017-1383-2

7. A. Popov, I. Bugay, P. Nazarov, O. Evdokimova, P. Popov, E. Vasilyev, Research of thread rolling on difficult-to-cut material workpieces. J. Phys. Conf. Ser. 944, 012091-012094 (2018). https://doi.org/10.1088/1742-6596/944/1/012091

8. H.W. Lee, J.H. Song, G.A. Lee, H.J. Lee, K.D. Park, Thread forming of a micro screw for storage devices using finite element analysis. Adv. Mater. Res. 264-265, 1613-1618 (2011). https:// doi.org/10.4028/www.scientific.net/AMR.264-265.1613

9. P. Kramer, P. Groche, Defect detection in thread rolling processes - Experimental study and numerical investigation of driving parameters. Int. J. Mach. Tools Manuf. 129, 27-36 (2018). https://doi.org/10.1016/j.ijmachtools.2018.02.004

10. H. Fransplass, M. Langseth, O.S. Hopperstad, Numerical study of the tensile behaviour of threaded steel fasteners at elevated rates of strain. Int. J. Impact. Eng. 54, 19-30 (2013). https://doi.org/10. 1016/j.ijimpeng.2012.10.009

11. H. Fransplass, M. Langseth, O.S. Hopperstad, Tensile behaviour of threaded steel fasteners at elevated rates of strain. Int. J. Mech. Sci. 53(11), 946-957 (2011). https://doi.org/10.1016/j.ijmecsci. 2011.07.006

12. Z. Pater, A. Gontarz, W. Weroñski, New method of thread rolling. J. Mater. Process. Technol. 153-154(1-3), 722-728 (2004). https://doi.org/10.1016/j.jmatprotec.2004.04.154

13. M. Tudor, M. Iordache, I. Ungureanu, E. Niţu, D. Iacomi, Ş Tabacu, Finite element modelling of cold rolling by flat wedge of circular grooves. Acad. J. Manuf. Eng. 9(4), 106-111 (2011)

Publisher's Note Springer Nature remains neutral with regard to jurisdictional claims in published maps and institutional affiliations. 